\title{
An Exploration of Foreign Language Anxiety and English Learning Motivation
}

\author{
Meihua Liu and Wenhong Huang \\ Department of Foreign Languages and Literatures, Tsinghua University, Beijing 100084, China \\ Correspondence should be addressed to Meihua Liu, ellenlmh@gmail.com
}

Received 25 August 2010; Revised 12 November 2010; Accepted 18 December 2010

Academic Editor: John C. K. Lee

Copyright ( $\odot 2011$ M. Liu and W. Huang. This is an open access article distributed under the Creative Commons Attribution License, which permits unrestricted use, distribution, and reproduction in any medium, provided the original work is properly cited.

\begin{abstract}
Perceived to be two important affective variables, anxiety and motivation have been found to be highly correlated to second/foreign language acquisition. In order to examine the relationship between foreign language anxiety, English learning motivation, and performance in English, the present study investigated 980 undergraduate students from three universities in China who answered a 76-item survey. Analyses of the data revealed that (1) the respondents generally did not feel anxious in English and were moderately motivated to learn English, (2) foreign language anxiety and English learning motivation were significantly negatively correlated with each other, and (3) both foreign language anxiety and English learning motivation were significantly correlated with students' performance in English. Among the scales, foreign language classroom anxiety (FLCAS), intrinsic motivation (IntrinM), instrumental motivation (InstruM), fear of being negatively evaluated (FLCAS1), and interest in foreign languages and cultures (IFLC) proved to be powerful predictors for the latter.
\end{abstract}

\section{Introduction}

Anxiety, one of the most prominent and pervasive emotions, was defined as a feeling of uneasy suspense by Rachman [1] and has been a focus of research in foreign language education since early 1970s. Over the years, state anxiety, trait anxiety, and situation-specific anxiety have become three mainstream approaches to anxiety research in language teaching and learning [2-4]. As Speilberger [4] distinguished, state anxiety was transitory and fluctuated over time and situation, while trait anxiety was relatively stable all the time.

Among situation-specific anxieties, foreign language classroom anxiety has been extensively researched $[2,3,5-$ 10] since Horwitz et al. [2] advanced a theory of foreign language classroom. They believed foreign language anxiety was responsible for students' negative emotional reactions to language learning since they had to deal with a totally foreign language and culture. They identified three components of foreign language classroom anxiety: communication apprehension, fear of negative evaluation, and test anxiety. To measure the anxiety, they designed the 33-item Foreign Language
Classroom Anxiety Scale (FLCAS). Gardner [5] had also acknowledged that second/foreign language (SL/FL) anxiety was situation-specific and claimed that individual differences in anxiety contributed to differences in achievement. The French Use Anxiety Scale and French Class Anxiety Scale were proposed $[3,5,9]$ to measure this anxiety.

Since then, studies on foreign language anxiety have been flourishing, using the FLCAS, or other scales, or other datacollecting instruments such as diaries, journals, interviews, and observations $[6,8,11-18]$. The studies have revealed that foreign language anxiety, though sometimes facilitating [11, $12,19,20]$, is predominantly debilitating in SL/FL learning $[2,3,7,9,10,12,15,21]$. For example, high-anxious students tend to perform worse than their low-anxious peers; they also tend to speak (more) briefly and sometimes even inaudibly. Highly anxious learners can even speak with shaking hands and/or legs; some even go blank when having to speak the target language. Thus, many choose to remain silent in class and thus their oral proficiency in the target language just falls down or becomes lower, as found in Liu's [12, 13] studies. Meanwhile, all types of SL/FL anxiety have been evidenced to be correlated to confidence and self-esteem, 
attitude, motivation, and cultural differences, and so forth $[3,6,12,14,22]$.

Likewise, motivation has also been widely researched on and agreed to be an important affective variable influencing SL/FL learning [5, 23-31]. Over the decades, several motivation theories on language learning have been proffered, the most widely recognized being the social-educational model $[5,32]$, the process-oriented model $[23,25,33]$, the self-determination theory proposed by Deci and Ryan, as discussed in Dörnyei [33], and the achievement motivation theory [23-25]. The core concept of the theories is that motivation is influenced by attitudes towards and orientations to learn a SL, that motivation, especially integrative or intrinsic motivation, boosts SL/FL learning and maintains learners' efforts to learn the language, and that motivation interacts with self-confidence, language anxiety, self-efficacy, causal attributions, L2 competence, and other variables. This has been confirmed by numerous empirical studies which expose that motivation has a direct effect on anxiety, self-efficacy, self-confidence, and second language achievement $[16,34]$, that integrative motivation is closely related to persistence, language attrition and retention $[28,35]$, and that intrinsic motivation contributes more to achievements in learning a second language than instrumental motivation [36, 37]. Liu's [38] study of 547 Chinese university students revealed that the more anxious student tended to be less motivated to learn English, which supported a similar finding in Hao et al. [39]. In addition, achievement motivation is found to be positively correlated to risk taking, persistence, and competence while negatively correlated to test anxiety [39, 40]. Meanwhile, many EFL learners self-reported to be more instrumentally than integratively motivated [28, 41-43].

As reviewed, both anxiety and motivation play an important role in affecting language learning outcomes, meanwhile, they are closely related to each other in SL/FL acquisition. Even so, studies on language anxiety and motivation simultaneously in a language learning context seem to be relatively scant so far. Thus, more research is called for in this area to determine how and to what extent foreign language anxiety and motivation interact with each other to affect language learning outcomes. It is especially so in foreign language learning contexts where learners normally have little access and exposure to the target language. In these contexts, they learn the target language mainly for a concrete purpose such as school requirement and finding a better job in the future. When having to use the language, they often become upset, nervous, and even panicked due to little practice. This is usually the case in China where EFL learners have little use of English in their daily life despite that increasing importance has been attached to the language. Therefore, the present study, situated in Chinese university EFL contexts, attempted to investigate the relationship between foreign language anxiety and motivation in relation to their interactive effect on performance in English. And the following research questions are of particular interest:

(1) what are the broad profiles of the Chinese university students' foreign language anxiety and motivation?
(2) how are foreign language anxiety and motivation related to each other?

(3) how do foreign language anxiety and motivation affect performance in English?

\section{Research Design}

2.1. Participants. The participants were 980 (617 male and 363 female) first-year non-English majors from various disciplines such as law, engineering, mechanics, and economics and management at three universities in China. All were enrolled in credit-bearing and compulsory English courses offered by their universities. With an age range from 13 (only one extremely exceptional student) to 21 and an average age of 18.49 , the majority $(470 / 48 \%)$ of the participants aged 18 , followed by the group aged $19(330 / 33.7 \%)$, and then came the groups aged $20(102 / 10.4 \%)$ and $17(60 / 6.1 \%)$, respectively.

2.2. Instrument. For this study, the students completed a survey consisting of a 36-item Foreign Language Classroom Anxiety Scale, a 40-item English Learning Motivation Scale, and the background questionnaire, as detailed below. All the items except the background questionnaire items were placed on a 5-point Likert scale ranging from "strongly disagree" to "strongly agree".

2.2.1. The Foreign Language Classroom Anxiety Scale. This 36-item Foreign Language Classroom Anxiety Scale was directly adopted from that in Liu's [13] and Liu and Jackson's [8] studies which was adapted from the scale developed by Horwitz et al. [2]. As theorized by Horwitz et al. [2], the FLCAS intended to measure three dimensions of foreign language classroom anxiety: fear of negative evaluation (FLCAS1) comprising 12 items which were reflective of fear of being negatively evaluated, communication apprehension (FLCAS2) consisting of 7 items which indicated apprehension of speech communication, and test anxiety (FLCAS3) having 2 items suggestive of fear of English tests.

2.2.2. English Learning Motivation Scale. This 40-item English Learning Motivation Scale (ELMS) was designed with reference to several sources [44-46] to measure six dimensions of motivation: motivation intensity, intrinsic motivation, language requirement, instrumental motivation, integrative motivation, and interest in foreign languages and cultures.

Strength of motivation was included because students might not really work hard to learn the language even though they had the motivation to learn English for various reasons. The 6-item Strength of Motivation (SOM) used in Liu's [38] study aimed to measure learners' motivation intensity. The 6-item Intrinsic Motivation (IntrinM) was adopted from Schmidt and Watanabe [45] to index to what extent learners were intrinsically motivated to learn English. The 1-item Language Requirement (LR) was incorporated in the ELMS because it was a fact that at least one English course was required with credits at each university. 
TABLE 1: Characteristics of instruments $(N=980)$.

\begin{tabular}{lccc}
\hline $\begin{array}{l}\text { Name of the } \\
\text { instrument }\end{array}$ & No. of items & Reliability & $\begin{array}{c}\text { Mean } \\
\text { item-total } \\
\text { correlation } \\
(P=.01)\end{array}$ \\
\hline FLCAS & 36 & .921 & .582 \\
FLCAS1 & 12 & .81 & .521 \\
FLCAS2 & 7 & .744 & .391 \\
FLCAS3 & 2 & .46 & .32 \\
SOM & 6 & .591 & .210 \\
IntrinM & 6 & .772 & .241 \\
InstruM & 11 & .751 & .385 \\
IntegM & 12 & .880 & .475 \\
IFLC & 4 & .741 & .325 \\
ELMS & 40 & .891 & .451 \\
\hline
\end{tabular}

Note: The reliability and mean item-total correlation of LR were not calculated since it had only 1 item.

Both the 11-item Instrumental Motivation (InstruM) and the 12-item Integrative Motivation (IntegM) were adopted from Vandergrift [46] and Noels et al. [44] studies with repetitious items deleted to measure to what extent learners were instrumentally and integratively motivated to learn English, respectively. Finally, the 4-item Interest in Foreign Languages and Cultures (IFLC) was adopted from Schmidt and Watanabe's [45] study to examine how learners were interested in foreign languages and cultures.

Preliminary statistical analyses revealed high internal consistency for the measures (see Table 1).

2.2.3. Background Information. The background questionnaire aimed to gather the respondents' demographic information such as name, gender, department, university, and English-learning time.

2.2.4. Performance in English. All the participants' scores in the course final exam taken in the last (16th) week of the term were collected as their performance in English [13]. The exam consisted of listening, reading, and writing (speaking was excluded because it was time consuming), but only the total score was used in the present study.

2.3. Procedure. The survey was administered to 30 intact classes of first-year undergraduate non-English majors at three universities in the 14th week of the first 16-week term of an academic year. The survey was competed in about 13 minutes. Of 1121 collected questionnaires, 980 were complete for further statistical analyses.

2.4. Data Analysis. For each measure, the mean, standard deviation, median, mode, and score range were calculated to determine to what extent the students felt anxious in English language classrooms and/or how they were motivated to learn English. Then, correlational analyses and regression analyses were run to explore the relationship between foreign language anxiety, motivation, and their predictive effect on the students' performance in English.

\section{Results and Discussion}

3.1. Broad Profiles of the Students' Foreign Language Anxiety and English Learning Motivation. To explore the broad profiles of the students' foreign language anxiety and English learning motivation, the researchers computed the mean, standard deviation, median, mode, score range, skewness and kurtosis of each scale. When doing so, the researchers adjusted the values assigned to the items reflective of little anxiety in foreign language class, or no motivation. Thus, the higher the FLCAS score, the more anxious the respondent reportedly felt; the higher the FLCAS1 score, the more $\mathrm{s} / \mathrm{he}$ feared being negatively evaluated; the higher the FLCAS2 score, the more apprehensive s/he was of speech communication; the higher the FLCAS3 score, the more worried s/he was about English tests. Similarly, the higher the ELMS score and its subscale scores, the more motivated the respondent reportedly was to learn English for various reasons.

Having 36 items with values of 1 to 5 assigned to the five descriptors of each item, respectively, the FLCAS has a possible score range of 36 to 180 . A total score of more than 144 on the FLCAS implies high anxiety, a total score of 108 to 144 signifies moderate anxiety, and a total score of less than 108 indicates no/little anxiety in English language classrooms. Likewise, a total score of more than 68 on the 12 -item FLCAS1 suggests a strong fear, a total score of 36 to 68 indicates moderate fear, and a total score of less than 36 reflects no/little fear of being negatively evaluated. Regarding the 7-item FLCAS2, the score ranges for being strongly, moderately, and strongly/moderately not apprehensive of speech communication, respectively, are more than $28,21-$ 28 , and less than 21 . The score ranges for a student to be strongly, moderately, and not anxious about English tests, respectively, are above 8,6-8, and below 6 for the 2-item FLCAS3. Similarly, the score ranges for great, moderate, and low strength of motivation or intrinsic motivation are more than $24,18-24$, and less than 18 , respectively, on the 6-item SOM or IntrinM. Likewise, a total score of more than 44 on the 11-item InstruM implies high instrumental motivation, a total score of 33 to 44 represents moderate and a total score of below 33 indicates low instrumental motivation. The score ranges for high, moderate, and low integrative motivation are more than 48, 36-48 and less than 36, respectively, on the 12item IntegM. And the score ranges for high, moderate, and low interest in foreign languages and cultures are more than $16,12-16$ and less than 12 , respectively, on the 4 -item IFLC. The results are summarized in Table 2 .

As shown in Table 2, the students achieved a mean of 99.79 (SD = 18.71), a median of 100 , and a mode of 89 on the FLCAS, which all fell below the scale midpoint of 108, indicating that the respondents generally did not experience anxiety in English classrooms. Meanwhile, the FLCAS1 had a mean of 33.51, a median of 34 , and a mode of 36; the FLCAS2 enjoyed a mean of 19.92 , a median of 20 and a mode of 19; and the FLCAS3 possessed a mean of 5.48, 
TABLe 2: Statistical analyses of the measured scales $(N=980)$.

\begin{tabular}{|c|c|c|c|c|c|c|c|}
\hline Measure & Mean & SD & Median & Mode & Range & Skewness & Kurtosis \\
\hline FLCAS1 & 33.51 & 6.88 & 34 & 36 & $12-59$ & -.067 & -.009 \\
\hline FLCAS2 & 19.92 & 4.38 & 20 & 19 & $7-35$ & -.003 & .092 \\
\hline FLCAS3 & 5.48 & 1.59 & 6 & 6 & $2-10$ & .163 & -.224 \\
\hline FLCAS & 99.79 & 18.72 & 100 & 89 & $36-172$ & -.021 & .380 \\
\hline SOM & 21.24 & 3.42 & 21 & 22 & $6-30$ & -.285 & .571 \\
\hline IntrinM & 19.26 & 4.18 & 19 & 19 & $6-30$ & -.122 & .036 \\
\hline LR & 2.62 & 1.13 & 2 & 2 & $1-5$ & .348 & -.952 \\
\hline InstruM & 35.95 & 5.95 & 36 & 39 & $14-53$ & -.444 & .785 \\
\hline IntegM & 37.32 & 8.13 & 37 & 36 & $12-60$ & -.164 & .033 \\
\hline IFLC & 14.69 & 2.83 & 15 & 16 & $4-20$ & -.875 & 1.701 \\
\hline ELMS & 131.08 & 17.68 & 131 & 127 & 55-184 & -.177 & .778 \\
\hline
\end{tabular}

a median and a mode of 6.00. Generally speaking, all the subscale scores barely exceeded their scale midpoints (36, 21, and 6 for the FLCAS1, FLCAS2, and FLCAS3, resp.). This further confirms the result of the FLCAS data that the participants generally did not feel anxious in English class, fearful of being negatively evaluated, or apprehensive about both speaking and tests, as found in studies with students of similar backgrounds $[8,43]$. This, as discussed in $[8,43]$, might be attributed to the fact that these learners had been learning English for more than six years suppose they started to learn the language in junior high school or even longer since the primary school or even kindergarten, although the language was seldom used in their daily life. Even so, it should be noted that the respondents in the present study reported to be less anxious than those in existing studies in similar Chinese EFL contexts [8, 13, 14, 43, 47, 48]. This might be partially explained by the fact that Chinese EFL learners have attached increasing importance to English in recent years as the country interacts with the world more and more frequently, which results in higher proficiency, more confidence, and less anxiety in English learning.

As seen from Table 2, the respondents obtained a mean of 131.08, a median of 131, and a mode of 127 on the ELMS, all highly above the scale midpoint 120, suggesting that the majority of the participants were moderately or even strongly motivated to learn English, as found in existing studies in similar Chinese EFL contexts [28, 43, 49]. This is not surprising in that Chinese EFL learners have been increasingly aware of the importance in English as globalization speeds up in recent years.

Meanwhile, a mean of 21.24 on SOM, 35.95 on InstruM, and 14.69 on IFLC, respectively, coupled with their medians and modes which all well exceeded their scale midpoints (18, 33 and 12 for SOM, InstruM and IFLC, resp.), imply that the participants had a moderate or even strong strength of motivation, were moderately or strongly instrumentally motivated, and were moderately or strongly interested in foreign languages and interacting with people from many cultures, consistent with the findings in Liu's [28] and Yang et al.'s [43] studies. As a global lingua franca, the importance of English has been well realized by Chinese educators and learners, as evidenced in the newly postulated College English Course Teaching Requirement [50]. Accordingly, as Chinese people know more about the world, they have become more interested in knowing foreign languages and cultures. Also, it is understandable that the participants were fairly motivated to learn English for various pragmatic reasons such as for a better job, more money, high marks, and personal development, as found in a range of other studies $[5,24,28,43,44,51,52]$.

In addition, a mean of 19.26 on IntrinM, a mean of 37.32 on IntegM, both slightly above the scale midpoints 18 and 36, respectively, show that the respondents were only moderately intrinsically as well as integratively motivated to learn English, contrary to Liu's [28] but consistent with Lamb's [53] (which studied integrative motivation of 219 Indonesian high school students) and Yang et al.'s [43] findings. To these learners, it was not a (high) priority to enjoy learning and using English in or outside the classroom, which might be due to their heavy load of major study. Nor would they attach such feelings as guilt, satisfaction, and excitement to English learning. They were not much motivated to learn English to become similar to a native speaker, which might be because English, though important in certain ways, was still rarely used in their daily life.

Further, the students scored 2.62 on LR, with a median and mode of 2 , all below the scale midpoint 3 , implying that compulsory courses, contrary to our expectation, did not constitute a great motivation for them to learn English. This actually needs further research since it has been long held that taking compulsory courses contributes to enhancing learners' English learning motivation.

Finally, a normal distribution can be observed for all the scales, as proved by the skewness and kurtosis values presented in Table 2. This lends further support to the finding that the respondents generally were not anxious in English language class and were moderately motivated to learn English for various reasons.

3.2. Correlations among the Measured Variables and the Students' Performance. Correlational analyses revealed the 
relationships between the students' foreign language anxiety, English learning motivation and their performance in English (see Table 3).

Table 3 shows that the FLCAS and its three subscales were all significantly negatively correlated with the ELMS and its six dimensions except for InstruM and LR $(r=-.155 \sim-.470, P<.01)$, as found in earlier studies [38, 39]. Students who scored high on the FLCAS and its subscales tended to score low on the ELMS and its subscales. Alternatively, students who were more anxious in English language class, more fearful of being negatively evaluated (FLCAS1), more apprehensive about public speaking (FLCAS2), and more anxious about tests (FLCAS3), tended to be less motivated to learn English intrinsically, instrumentally, and/or integratively. They had lower motivation intensity as well as less interest in foreign languages and cultures. Meanwhile, the FLCAS and its subscales were significantly positively related to LR, with coefficients ranging from .206 to 309 $(P<.01)$. Namely, a more anxious student was more likely to be motivated by language requirement to learn English.

Finally, all the scales except for InstruM were significantly related to the students' performance in English, with coefficients ranging from -.317 to $.279(P<.05)$, though the coefficients were not high. Among the variables, the FLCAS and its three subscales were all significantly negatively correlated with the latter $(r=-.247 \sim-.317, P<.05)$, as found in numerous existing studies [2, 10, 13, 16, 21, 54]. The ELMS and its subscales except for LR and InstruM were all positively correlated with the latter, with a coefficient range of .072 to $.152(P<.05)$, consistent with that in Liu [38], while LR was significantly negatively related to the latter $(r=-.294, P<.01)$. In other words, the more a student worried about the English language class, the worse s/he performed in English. By contrast, the more motivated s/he was intrinsically, integratively and/or by interest in foreign languages and cultures, the better s/he performed in English. However, if a respondent was more motivated by language requirement, s/he tended to perform worse in English or vice versa.

The analyses so far clearly support the conclusion that foreign language anxiety and English learning motivation were closely related to each other and the students' performance in English.

3.3. The Regression Model. The results of the correlational analyses discussed previously show numerous bivariate relationships, which could not indicate the influence of one variable on another. Better clues were provided by multiple regression analyses. A stepwise method was employed in forming regression models. Altogether 5 models resulted with the change in $R^{2}$ being all significant: .100 for model 1 (FLCAS) $(P=.000), .022$ for model 2 (FLCAS and IntrinM) $(P=.000), .007$ for model 3 (FLCAS, IntrinM, and InstruM) $(P=.005), .005$ for model 4 (FLCAS, IntrinM, InstruM, and FLCAS1) $(P=.025)$, and .004 for model 5 (FLCAS, IntrinM, InstruM, FLCAS1, and IFLC) $(P=.031)$. The results are summarized in Table 4 , which reports coefficients from the regression models as well as their levels of significance. As can be seen, all the coefficients were statistically significant.
Table 4 shows that five of the measured variables were included in the models in terms of performance in Englishforeign language classroom anxiety (FLCAS), intrinsic motivation (IntrinM), instrumental motivation (InstruM), fear of being negatively evaluated (FLCAS1), and interest in foreign languages and cultures (IFLC). Among these five variables, FLCAS was the most powerful predictor of students' performance in English $(\beta=-.394, t=-4.63$, $P=.000)$, followed by IntrinM $(\beta=.141, t=3.756$, $P=.000)$, InstruM $(\beta=-.116, t=-3.615, P=$ $.000)$, the FLCAS1 $(\beta=.177, t=2.189, P=.029)$, and IFLC ( $\beta=.077, t=2.162, P=.031)$. The FLCAS and InstruM were negative predictors, whereas the other three were positive ones. It is understandable that a more anxious respondent was more likely to perform worse in English; but a more instrumentally motivated respondent tended to perform worse in English as well might be because s/he had to worry about whether his/her goal could be achieved when performing in the language. Meanwhile, the respondent who was more intrinsically motivated, more interested in foreign languages and cultures, and/or more fearful of negative evaluation were more inclined to do better in the English exam. Unexpectedly, as happened in Liu and Zhang [21], the FLCAS1 became a positive predictor but InstruM became a negative one for the students' performance in English, contrary to the results of correlational analyses. This might be because when working alone, the FLCAS1 could negatively affect students' performance in English and InstruM boosted the latter, while when interweaving with other variables, their influence on the latter became complicated. In the present study, anxiety proved to be the most influential factor affecting the students' performance in English, which was probably because the language was scarcely used outside the language class in their daily life though they were usually motivated to learn it. In spite of this, the fear of being negatively evaluated motivated them to overcome a certain degree of anxiety and impelled them to perform better in the exam. Contrary to this, instrumentally motivated students might constantly relate their performance to their learning purposes; this might aggravate their feeling of anxiety, which resulted in poorer performance in the exam. All these explanations, however, needs to be further validated with qualitative data such as interview and journal reports.

\section{Conclusions and Implications}

Several conclusions can be warranted from the present study of the relationship between students' foreign language anxiety, English motivation, and performance in English.

First, the analyses exposed that the respondents generally did not feel anxious in English class, fearful of being negatively evaluated, or apprehensive about both speaking and tests. Meanwhile, the majority of the participants were moderately or even strongly motivated to learn English. They reported to have a moderate or even strong motivation intensity, be moderately or strongly instrumentally motivated, and be moderately or strongly interested in foreign languages and interacting with people from many cultures, though they 
TABLE 3: Correlations among the measured variables and performance $(N=980)$.

\begin{tabular}{|c|c|c|c|c|c|c|c|c|c|c|c|}
\hline Variable & FLCAS2 & FLCAS3 & FLCAS & SOM & IntrinM & LR & InstruM & IntegM & IFLC & ELMS & Performance \\
\hline FLCAS1 & $.739 * *$ & $.510^{* *}$ & $.925^{* *}$ & $-.325^{* *}$ & $-.363^{* *}$ & $.273^{* *}$ & .046 & $-.140^{* *}$ & $-.212^{* *}$ & $-.214^{* *}$ & $-.260^{*}$ \\
\hline FLCAS2 & 1 & $.468^{* *}$ & $.863^{* *}$ & $-.342^{* *}$ & $-.435^{* *}$ & $.263^{* *}$ & -.061 & $-.214^{* *}$ & $-.264^{* *}$ & $-.314^{* *}$ & $-.260^{*}$ \\
\hline FLCAS3 & & 1 & $.631^{* *}$ & $-.253^{* *}$ & $-.320^{* *}$ & $.206^{* *}$ & $-.095^{* *}$ & $-.155^{* *}$ & $-.209^{* *}$ & $-.248^{* *}$ & $-.247^{*}$ \\
\hline FLCAS & & & 1 & $-.398^{* *}$ & $-.470^{* *}$ & $.309^{* *}$ & -.017 & $-.210^{* *}$ & $-.286^{* *}$ & $-.317^{* *}$ & $-.317^{*}$ \\
\hline SOM & & & & 1 & $.483^{* *}$ & $-.345^{* *}$ & $.169^{* *}$ & $.352^{* *}$ & $.452^{* *}$ & $.577^{* *}$ & $.213^{*}$ \\
\hline IntrinM & & & & & 1 & $-.363^{* *}$ & $.174^{* *}$ & $.595^{* *}$ & $.483^{* *}$ & $.717^{* *}$ & $.279^{*}$ \\
\hline LR & & & & & & 1 & $.149^{* *}$ & $-.220^{* *}$ & $-.285^{* *}$ & $-.185^{* *}$ & $-.294^{*}$ \\
\hline InstruM & & & & & & & 1 & $.362^{* *}$ & $.339 * *$ & $.641^{* *}$ & -.050 \\
\hline IntegM & & & & & & & & 1 & $.577^{* *}$ & $.869^{* *}$ & $.143^{*}$ \\
\hline IFLC & & & & & & & & & 1 & $.723^{* *}$ & $.182^{*}$ \\
\hline ELMS & & & & & & & & & & 1 & $.166^{*}$ \\
\hline
\end{tabular}

Note: ${ }^{*} P<.01 ;{ }^{*} P<.05$.

TABLE 4: Regression coefficients and significance.

\begin{tabular}{lcccccc}
\hline & & FLCAS & IntrinM & InstruM & FLCAS1 & IFLC \\
\hline & $\beta$ & -.394 & .141 & -.116 & .177 & .077 \\
Performance & $t$ & -4.63 & 3.756 & -3.615 & 2.189 & 2.162 \\
in English & $P$ & .000 & .000 & .000 & .029 & .031 \\
& VIF & 8.174 & 1.592 & 1.157 & 7.396 & 1.446 \\
\hline
\end{tabular}

were only moderately intrinsically as well as integratively motivated to learn English. Language requirement did not constitute a great motivation for them to learn English either. Secondly, foreign language anxiety and English learning motivation were significantly negatively correlated with each other. For example, a more anxious respondent tended to be less intrinsically motivated but more motivated by language requirement. Finally, both foreign language anxiety and English learning motivation were significantly correlated with students' performance in English. Among the scales, foreign language classroom anxiety (FLCAS), intrinsic motivation (IntrinM), instrumental motivation (InstruM), fear of being negatively evaluated (FLCAS1), and interest in foreign languages and cultures (IFLC) proved to be powerful predictors for the latter.

As such, for the purpose of bettering students' performance in English, it is necessary for language teachers as well as learners to take measures to alleviate anxiety levels, since anxiety turned out to be the most powerful and negative predictor for the students' performance in English. Setting realistic and achievable goals, building a relaxing classroom environment, sharing language learning experiences and feelings, providing more chances to learners to use the language, encouraging and praising learners often, and so on, have been recommended to be effective in reducing anxiety levels $[12,14,38,55-58]$. Nevertheless, as the analyses showed that fear of being negatively evaluated might become a positive predictor of performance in English in the present study, language teachers and learners had better be cautious when trying to cope with anxiety. It may be conducive to learning if learners are kept under certain pressure when working on a particular task. Meanwhile, (over)emphasizing learning English for utilitarian purposes may result in (extra) pressure and anxiety in the learners, which may ultimately debilitate their performance in English, as found in the present study. On the contrary, intrinsic motivation and interest in foreign languages and cultures proved to be positive predictors of students' performance in English, as predicted by Gardner and his associates [5, 27, 35]. Thus, enhancing learners' interest in English and its culture is more important to promote their learning of the language. With a better knowledge of the language and its culture, the learners may not feel so foreign and strange when using the language. Consequently, it is less likely for them to become anxious and fidgeted then. Likewise, it is beneficial to boost learners' overall motivation to learn the target language. Promoting students' awareness of the importance of English, enhancing students' interest in English, developing their self-confidence, fostering their positive attitudes towards English, praising them/giving positive feedback, analyzing reasons for poor/good performance in English, fostering their intrinsic motivation in English by encouraging them to read English literary works, watching English films, and making friends with international students on campus, and so forth are suggested to be good ways to enhance students' English learning motivation [33, 38, 59, 60]. With enhanced motivation to learn English, students may become more willing and active to use the language in various situations, which may in return result in lower anxiety in English learning.

Finally, since the present study was positioned in a typical EFL context, the findings and implications can be generalized to other similar EFL contexts in the country, in Asia or even other parts of the world. However, it might also be probable, for example, that students may be less anxious when speaking English at institutions where students generally have (much) less access and exposure to the language and are not motivated to learn it, since they are not expected to be highly competent in the language. Thus, investigations in a variety of settings with students who have differing backgrounds are urgently needed to better understand the relationship 
between anxiety, motivation, and performance in the target language and offer context-appropriate advice.

\section{Acknowledgment}

The present study was sponsored by Asia Research Center in Tsinghua University in 2010.

\section{References}

[1] S. Rachman, Anxiety, Psychology Press, Hove, East Sussex, UK, 1998.

[2] E. K. Horwitz, M. B. Horwitz, and J. Cope, "Foreign language classroom anxiety," The Modern Language Journal, vol. 70, pp. 125-132, 1986.

[3] P. D. MacIntyre and R. Gardner, "Methods and results in the study of anxiety and language learning: a review of the literature," Language Learning, vol. 41, pp. 85-117, 1991.

[4] C. D. Spielberger, "Anxiety as an emotional state," in Anxiety: Current Trends in Theory and Research, C. D. Spielberger, Ed., vol. 1, pp. 3-19, Academic Press, New York, NY, USA, 1972.

[5] R. C. Gardner, Social Psychology and Second Language Learning: The Role of Attitudes and Motivation, Edward Arnold, London, UK, 1985.

[6] M. Hilleson, "I want to talk with them, but I don't want them to hear: an introspective study of second langue anxiety in an English-medium school," in Voices from the Language Classroom, K. M. Bailey and D. Nunan, Eds., pp. 248-282, Cambridge University Press, Cambridge, UK, 1996.

[7] K. Horwitz, "Language anxiety and achievement," Annual Review of Applied Linguistics, vol. 21, pp. 112-126, 2001.

[8] M. Liu and J. Jackson, "An exploration of Chinese EFL learners' unwillingness to communicate and foreign language anxiety," The Modern Language Journal, vol. 92, no. 1, pp. 7186, 2008.

[9] P. D. MacIntyre and R. Gardner, "The subtle effects of language anxiety on cognitive processing in the second language," Language Learning, vol. 44, pp. 283-305, 1994.

[10] D. J. Young, "The relationship between anxiety and foreign language oral proficiency ratings," in Language Anxiety: From Theory to Classroom Implications, E. K. Horwitz and D. J. Young, Eds., pp. 57-63, Prentice-Hall, Englewood Cliffs, NJ, USA, 1991.

[11] K. M. Bailey, "Competitiveness and anxiety in adult second language learning: looking at and through the dairy studies," in Classroom Oriented Research in Second Language Acquisition, H. W. Seliger and M. H. Long, Eds., pp. 67-103, Newbury House Publishers, Rowley, Mass, USA, 1983.

[12] M. Liu, "Anxiety in EFL classrooms: causes and consequences," TESL Reporter, vol. 39, pp. 13-32, 2006.

[13] M. Liu, "Anxiety in Chinese EFL students at different proficiency levels," System, vol. 34, no. 3, pp. 301-316, 2006.

[14] M. Liu, "Anxiety in oral English classrooms: a case study in China," Indonesian Journal of English Language Teaching, vol. 3, pp. 119-137, 2007.

[15] M. Liu, "Anxiety in oral English testing situations," ITL. International Journal of Applied Linguistics, vol. 153, pp. 5376, 2007.

[16] M. Liu and Y. Hu, "Reading anxiety in EFL classrooms: a case study," in Proceedings of the 3rd International Symposium on Teaching English at Tertiary Level, pp. 48-56, Hong Kong, 2009.
[17] V. D. Sellers, "Anxiety and reading comprehension in Spanish as a foreign language," Foreign Language Annals, vol. 33, no. 5, pp. 512-520, 2000.

[18] J. X. Yan and E. K. Horwitz, "Learners' perceptions of how anxiety interacts with personal and instructional factors to influence their achievement in English: a qualitative analysis of EFL learners in China," Language Learning, vol. 58, no. 1, pp. 151-183, 2008.

[19] M. Liu and J. Jackson, "Reticence and anxiety in oral English lessons: a case study in Mainland China," in Researching Chinese Learners-Skills, Perceptions, and Intercultural Adaptation, L. Jin and M. Cortazzi, Eds., Palgrave MacMillan, Basingstoke, $\mathrm{UK}$, In press.

[20] R. Oxford, "Anxiety and language learner: new insights," in Affect in Language Learning, J. Arnold, Ed., pp. 260-278, Cambridge University Press, Cambridge, UK, 1999.

[21] M. Liu and W. Zhang, "An exploration of Chinese EFL learners' foreign language anxiety, personality and self-esteem," Journal of Applied Linguistics. In press.

[22] M. E. Ehrman and R. L. Oxford, "Cognition plus: correlates of language learning success," The Modern Language Journal, vol. 79, pp. 67-89, 1995.

[23] Z. Dörnyei, "Motivation in second and foreign language learning," Language Teaching, vol. 31, pp. 117-135, 1998.

[24] Z. Dörnyei, "New themes and approaches in second language motivation research," Annual Review of Applied Linguistics, vol. 21, pp. 43-59, 2001.

[25] Z. Dörnyei, Teaching and Researching Motivation, Longman: Pearson Education, Harlow, UK, 2001.

[26] Z. Dörnyei and P. Skehan, "Individual differences in second language learning," in The Handbook of Second Language Acquisition, T. J. Doughty and M. H. Long, Eds., pp. 589-630, Blackwell Publishing, T Malden, Mass, USA, 2003.

[27] R. C. Gardner and P. D. MacIntyre, "An instrumental motivation in language study," Studies in Second Language Acquisition, vol. 13, pp. 57-72, 1991.

[28] M. Liu, "Chinese students' motivation to learn English at the tertiary level," Asian EFL Journal, vol. 9, pp. 126-146, 2007.

[29] B. Spolsky, "Anniversary article language motivation revisited," Applied Linguistics, vol. 21, no. 2, pp. 157-169, 2000.

[30] X. Wang and W. Zhang, "Analysis of the research situation of foreign language learning motivation in China," Foreign Language World, vol. 108, pp. 58-66, 2005.

[31] Q. Wen, "Developmental patterns in motivation, beliefs and strategies of English learners in China," Foreign Language Teaching and Research, vol. 33, pp. 105-110, 2001.

[32] P. F. Tremblay and R. Gardner, "Expanding the motivational construct in language learning," The Modern Language Journal, vol. 79, pp. 505-518, 1995.

[33] Z. Dörnyei, "Motivation and motivating in the foreign language classroom," The Modern Language Journal, vol. 78, pp. 273-274, 1994.

[34] M. E. Ehrman, "An exploration of adult language learner motivation, self-efficacy, and anxiety," in Language Learning Motivation: Pathways to the New Century, R. Oxford, Ed., pp. 81-103, Second Language Teaching \& Curriculum Center, 1996.

[35] R. C. Gardner, R. Moorcroft, and J. Metford, "Second language learning in an immersion program: factors influencing acquisition and retention," Journal of Language and Social Psychology, vol. 8, pp. 287-305, 1989.

[36] K. Ramage, "Motivational factors and persistence in foreign language study," Language Learning, vol. 40, pp. 189-219, 1990. 
[37] A. E. Woolfolk, Educational Psychology, Allyn \& Bacon, Boston, Mass, USA, 4th edition, 1990.

[38] M. Liu, Reticence and Anxiety in Oral English Lessons, Peter Lang AG, Bern, Switzerland, 2009.

[39] M. Hao, M. Liu, and R. P. Hao, “An empirical study on anxiety and motivation in English as a foreign language," Asian Journal of English Language Teaching, vol. 14, pp. 89-104, 2004.

[40] A. J. Elliot and H. A. McGregor, "Test anxiety and the hierarchical model of approach and avoidance achievement motivation," Journal of Personality and Social Psychology, vol. 76, no. 4, pp. 628-644, 1999.

[41] Y. Gao, Y. Zhao, Y. Cheng, and Y. Zhou, "Motivation types of Chinese college undergraduates," Modern Foreign Languages, vol. 26, pp. 28-38, 2003.

[42] Y. Gao, Y. Zhao, Y. Cheng, and Y. Zhou, "The relationship between Chinese college undergraduates English learning motivational intensity and their self identity changes," Foreign Languages and Their Teaching, vol. 170, pp. 25-28, 2003.

[43] L. Yang, M. Liu, and W. Wu, "An investigation of Chinese undergraduate non-English majors' English learning motivation," in ELT at Tertiary Level in Asian Context: Issues and Researchers, Z. Lu, W. Zhang, and P. Adams, Eds., pp. 48-62, Tsinghua University, Beijing, China, 2010.

[44] K. A. Noels, R. Clément, and L. G. Pelletier, "Intrinsic, extrinsic, and integrative orientations of French Canadian learners of English," The Canadian Modern Language Review, vol. 57, no. 3, pp. 424-440, 2000.

[45] R. Schmidt and Y. Watanabe, "Motivation, strategy use, and pedagogical preferences in foreign language learning," in Motivation and Second Language Acquisition, Z. Dörnyei and R. Schmidt, Eds., p. 313-359, University of Hawaii Press, Honolulu, Hawaii, USA, 2002.

[46] L. Vandergrift, "Relationships among motivation orientations, metacognitive awareness and proficiency in L2 listening," Applied Linguistics, vol. 26, no. 1, pp. 70-89, 2005.

[47] H. Chen, College students' English learning anxiety and their coping styles, unpublished M.S. thesis, Southwest Normal University, 2002.

[48] C. Wang, "Report of the FLCAS in college students," Journal of Psychology Science, vol. 26, pp. 281-284, 2003.

[49] A. Yang and L. Lau, "Student attitudes to the learning of English at secondary and tertiary levels," System, vol. 31, no. 1, pp. 107-123, 2003.

[50] College English Course Teaching Requirement, Higher Education Press, Beijing, China, 2004.

[51] F. Belmechri and K. Hummel, "Orientations and motivation in the acquisition of English as a second language among high school students in Quebec City," Language Learning, vol. 48, no. 2, pp. 219-244, 1998.

[52] E. Ushioda, "Motivation and good language learners," in Lessons from Good Language Learners, C. Griffiths, Ed., pp. 1934, Cambridge University Press, Cambridge, UK, 2008.

[53] M. Lamb, "Integrative motivation in a globalizing world," System, vol. 32, no. 1, pp. 3-19, 2004.

[54] P. D. MacIntyre, S. C. Baker, R. Clément, and L. A. Donovan, "Sex and age effects on willingness to communicate, anxiety, perceived competence, and L2 motivation among junior high school French immersion students," Language Learning, vol. 53, no. 1, pp. 137-165, 2003.

[55] N. Anderson, "Narrowing the gap between perceived and actual performance through learner training in self assessment," in Paper Presented at the 1PstP Conference of Asian TEFL, Busan, South Korea, 2003.
[56] S. C. Baker and P. D. MacIntyre, "The role of gender and immersion in communication and second language orientations," Language Learning, vol. 50, no. 2, pp. 311-341, 2000.

[57] G. R. Johnson, First Steps to Excellence in College Teaching, Magna Publications, Madison, Wis, USA, 1995.

[58] A. B. M. Tsui, "Reticence and anxiety in second language learning," in Voices from the Language Classroom, K. M. Bailey and D. Nunan, Eds., pp. 145-167, Cambridge University Press, Cambridge, UK, 1996.

[59] R. Oxford and J. Shearin, "Language learning motivation: expanding the theoretical framework," The Modern Language Journal, vol. 78, pp. 12-27, 1994.

[60] R. J. Wlodkowski, Enhancing Adult Motivation to Learn, Jossey-Bass Publishers, Oxford, UK, 1990. 


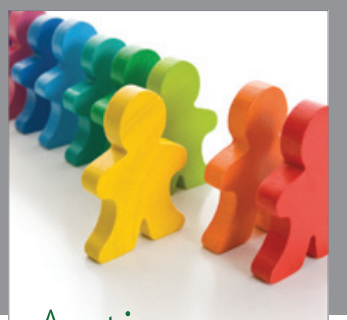

Autism

Research and Treatment
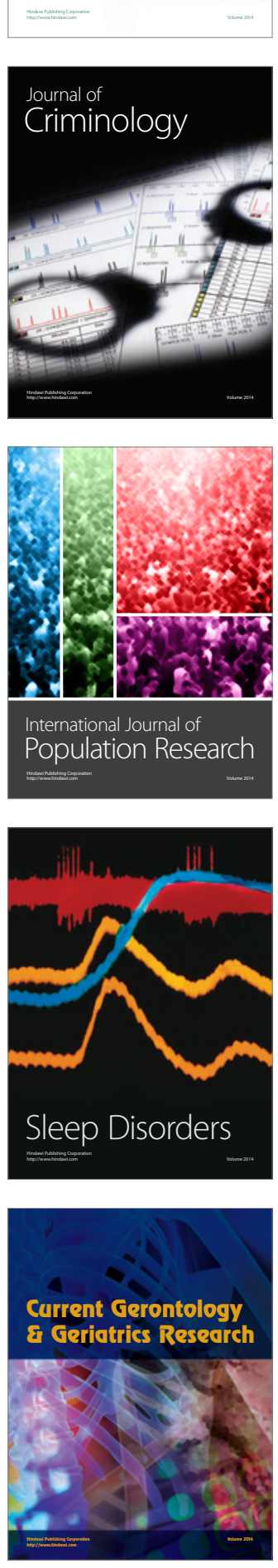
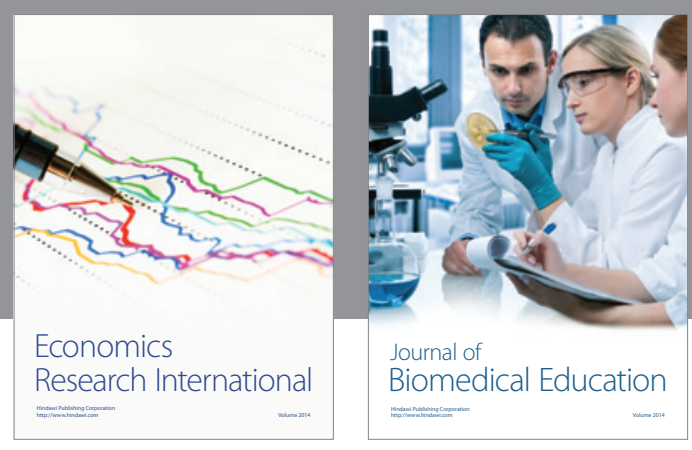

Journal of

Biomedical Education

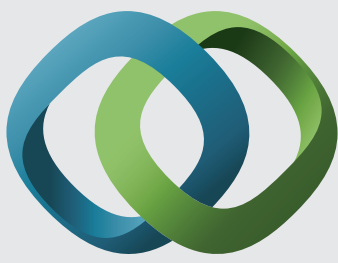

\section{Hindawi}

Submit your manuscripts at

http://www.hindawi.com
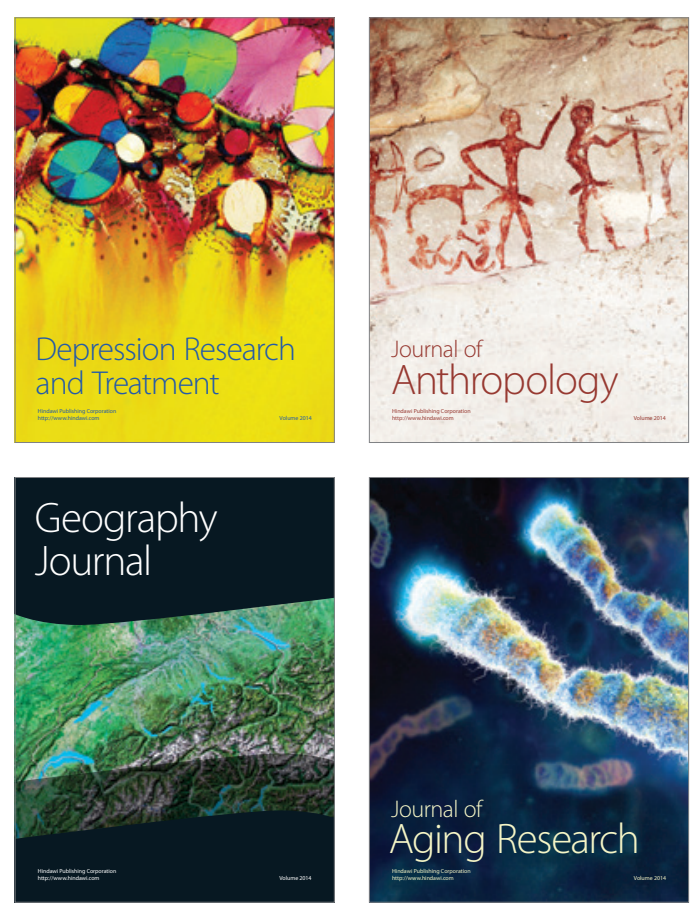

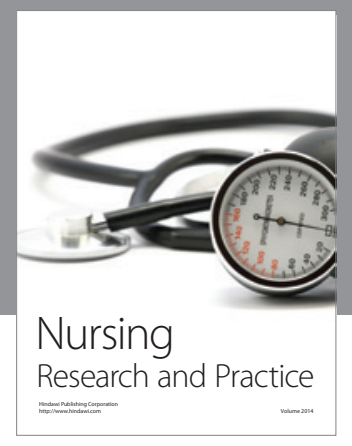

Nursing

Research and Practice

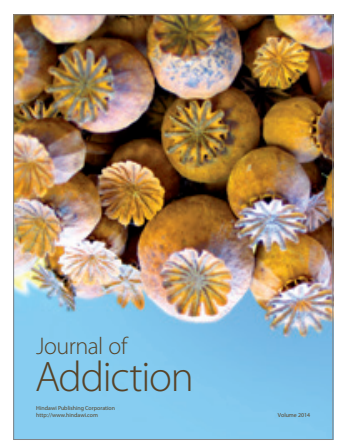

Child Development

Research

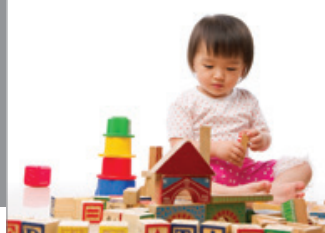

迥
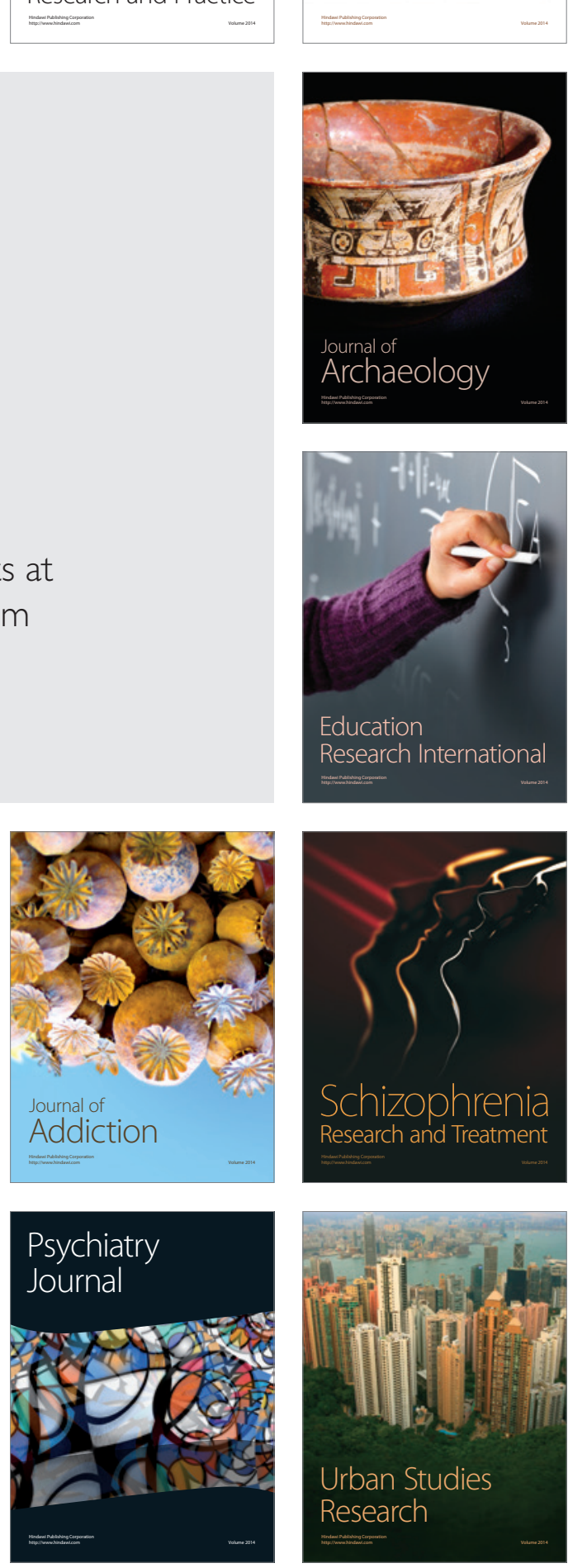